\title{
Isolation and Selection of Potentially Beneficial Autochthonous Bacteria for Piaractus mesopotamicus Aquaculture Activities
}

\section{Marcos Gabriel Guidoli ${ }^{1,3}$, Juan José Santinón ${ }^{1}$, Sergio Enrique Pasteris² ${ }^{2}$ Sebastián Sánchez ${ }^{1}$ and María Elena Fátima Nader-Macías ${ }^{3}$}

${ }^{1}$ Department of Veterinary Sciences, Institute of Northeast Ichthyology (INICNE), National University of the Northeast, Corrientes, Argentina

${ }^{2}$ Superior Institute of Biological Research (INSIBIO-CONICET), San Miguel de Tucuman, Argentina

${ }^{3}$ Reference Center Lactobacilli (CERELA-CONICET), San Miguel de Tucuman, Argentina

\begin{abstract}
Piaractus mesopotamicus is the most produced specie in Argentinian fish culture with an annual production of 2,017 tons. The high demands of specimens generated a deficit of larvae, juveniles and sexually mature adults. The high stress conditions and the incidence of diseases had intensified this deficit. Probiotics are proven to increase survival and growth rates in aquaculture. The first step in the design of a putative probiotic is the selection of adequate microorganisms to boost fish health. Lactic Acid Bacteria and Bacillus are generally accepted as probiotics in aquaculture. In this work we obtained 522 isolates from different anatomical parts of $P$. mesopotamicus, with a total of 30 lactic acid bacteria (LAB) and 8 Bacillus strains submitted for the evaluation of their beneficial properties. Only eight of these strains were selected for further "in vivo" assays based on following criteria: production of inhibitory metabolites and biosurfactants, screening of antagonistic activity against foodborne and pathogenic microorganisms, ability to emulsify polar solvents and compatibility between strains. All selected microorganisms were identified by sequencing $16 \mathrm{~S}$ RNA gene. Pure cultures of all strains herein studied are preserved in Centro de Referencia de Lactobacilos (CERELA-CONICET) and Laboratorio de Sanidad Animal of the Estación Experimental Agropecuaria Rafaela, Instituto Nacional de Tecnología Agropecuaria (INTA) culture collections.
\end{abstract}

Keywords: Piaractus mesopotamicus; Beneficial bacterial strains; Probiotics; Aquaculture; Lactic acid bacteria

\section{Abbreviations}

LAB: Lactic Acid Bacteria; GRAS: Generally Regarded As Safe; FGM: Food Grade Microorganisms; QPS: Qualified Presumption as Safe; TMB: 3,3',5,5'-Tetramethyl-Benzidine; MATH: Microbial Adhesion to Hydrocarbon Method; IG1: Indicators group 1

\section{Introduction}

Piaractus mesopotamicus, commonly known in South America as Pacú, Pez chato, Mirabí or Pirarí is a serrasalmid fish endemic to the Paraguay-Paraná river basin that has been incorporated to the aquaculture production system in the northern region of Argentina. The resistance of this autochthonous fish to the breeding conditions has led to a high increase in its production, turning it into the main produced fish in Argentina with 1345.32 tons, equivalent to $44.45 \%$ of the total aquaculture production in Argentina in 2012 [1]. However, the poor knowledge on the behavior of this specie and the conditions of the intensive and super intensive breeding systems have created a deficit in the number of animals at different stages of their biological cycle, mainly for the obtaining of larvae, juveniles and sexually mature adults.

The most worldwide proposed technique to increase the production in aquaculture facilities is the use of antibiotics. Besides acting as antiinfectious agents, antibiotics are associated with decreases in animal gut mass and increases in intestinal absorption and energy sparing; allowing a higher amount of consumed nutrients to be used for growth and production [2]. However, nowadays the use of antibiotics in aquaculture represents a human health risk characterized by three items: resistance transference [3], toxicity of antibiotic residues [4], allergies and effects of the antibiotics on human intestinal microbiota [2] and environmental risks [5].

A novel and emerging alternative to antibiotics are probiotics, defined for aquaculture as "a live microbial adjunct which has a beneficial effect on the host by modifying the host associated or ambient microbial community, by ensuring improved use of feed or enhancing its nutritional value, by enhancing the host response toward disease or by improving the quality of its ambient environment" [6]. Beneficial microorganisms have been used successfully all around the world with wide purposes in different aquatic cultures such as inhibitory activity against primary pathogens [7], immunostimulatory effect and nonspecific immune response stimulation [8]; decrease of mortality and reduction of the infection of animals infected with different pathogens and increased rate of growth in turbot [9], atlantic salmon [10], rainbow trout [11] and Pacific oyster [12] and increase of production in channel catfish [13].

The selection of beneficial microorganisms to be included in a probiotic product is a critical step. An ideal probiotic strain should be able to colonize, establish and multiply in the host mucosa [14]. Therefore, there is a general consensus that microorganisms from autochthonous source have a higher possibility to colonize and compete with resident microbes, becoming predominant within a short period of intake. This could assist to the restoration of a disturbed microbiota and therefore enhance the host resistance to infectious diseases [4]. Lactic Acid Bacteria (LAB) and Bacillus are widely used as probiotics in aquaculture, showing a significant effect, as described by several authors $[4,15,16]$. They are also considered as microorganisms Generally Regarded as Safe (GRAS), Food Grade Microorganisms (FGM) and Qualified Presumption as Safe (QPS) bacteria.

Regarding specifically to $P$. mesopotamicus, there are no previous

*Corresponding author: María EF Nader-Macías, Reference Center Lactobacill (CERELA-CONICET), PC: T4000ILC, St Chacabuco 145, San Miguel de Tucuman, Argentina, Tel: +54 381 4310465; Fax: +54 381 4005600; E-mail: fnader@cerela.org.ar

Received August 23, 2015; Accepted September 11, 2015; Published September 16, 2015

Citation: Guidoli MG, Santinón JJ, Pasteris SE, Sánchez S, Nader-Macías MEF (2015) Isolation and Selection of Potentially Beneficial Autochthonous Bacteria for Piaractus mesopotamicus Aquaculture Activities. J Bioprocess Biotech 5: 254 doi:10.4172/2155-9821.1000254

Copyright: (c) 2015 Guidoli MG, et al. This is an open-access article distributed under the terms of the Creative Commons Attribution License, which permits unrestricted use, distribution, and reproduction in any medium, provided the original author and source are credited. 
description of the autochthonous microbiota or assays directed to evaluate the responses of this species to probiotic or beneficial bacteria treatments. Thus, the knowledge of the indigenous microbiome of this economically important specie is required. Therefore, the aim of this work was to determine the cultivable microbiota of $P$. mesopotamicus and to select beneficial microorganisms to be further included in the design of a pharmaceutical preparation to be applied in the aquaculture of P. mesopotamicus.

\section{Materials and Methods}

\section{Samples and isolation of cultivable microorganisms}

Samples were taken from P. mesopotamicus specimens at different stages of their biological cycle in a fishery located in facilities of the Universidad Nacional del Nordeste. The first isolation was performed in autumn from 10 fishes of approximately 4 months old with mean values of $9.23 \mathrm{~cm}$ long and $4.25 \mathrm{~g}$. Five of these animals belonged to a group affected with columnariasis disease (these isolates were not included into the potentially probiotic bacteria), while the other half were healthy specimens. For the second (summer) and third isolation (winter), 14 and 10 specimens, respectively, were sampled (Tables 1 and 2 ). The sampling process depended on the specimens weigh. Animals bigger than $5 \mathrm{~g}$ were sampled by scrapping dorsal and ventral skin (1 $\mathrm{cm}^{2}$ ), gills, anus and mouth. In these specimens, the anterior, middle and posterior intestine sections were homogenized by using a Teflon pestle at $750 \mathrm{rpm}$ in aseptic conditions. Small animals (weight $\leq 5 \mathrm{~g}$ ) specimens were homogenized in different quantities of sterile distilled water $(2 \mathrm{ml}$ for those under $1 \mathrm{~g}, 5 \mathrm{ml}$ for those between 1 and $3.5 \mathrm{~g}$ and $15 \mathrm{ml}$ for those between 3.5 and $5 \mathrm{~g}$ ) by using a Teflon pestle at $750 \mathrm{rpm}$ in aseptic conditions. Samples were collected in two culture media: LAPTg ( $1 \%$ yeast extract, $1.5 \%$ peptone, $1 \%$ tryptone, $1 \%$ glucose, $0.1 \%$ Tween 80; pH 7.2) and Nutrient Broth (0.5\% plurypeptone, $0.3 \%$ meet extract; $\mathrm{pH} 6.9$ ) and stored at $4^{\circ} \mathrm{C}$ until processing.

In order to isolate the spore-forming microorganisms, samples collected in Nutrient broth were heated at $80^{\circ} \mathrm{C}$ for $15 \mathrm{~min}$ and incubated for $3 \mathrm{hr}$ at $37^{\circ} \mathrm{C}$ and later 24 to $72 \mathrm{hr}$ at $37^{\circ} \mathrm{C}$ in Nutrient Agar (Nutrient broth added with $1.5 \% \mathrm{w} / \mathrm{v}$ agar). For the isolation of LAB, samples from LAPTg broth were inoculated in LAPTg agar $(1.5 \%$ $\mathrm{w} / \mathrm{v}$ ) for 24 to $72 \mathrm{hr}$ at $37^{\circ} \mathrm{C}$.

All plates were observed every $24 \mathrm{hr}$ during 3 days and selected colonies were subcultured and stored at $-20^{\circ} \mathrm{C}$ in their appropriate medium supplemented with $20 \%$ glycerol.

\section{Selection of beneficial microbial genera}

The isolates previously obtained were phenotypically characterized according to the following tests: Gram-Nicole staining, Schaeffer Fulton staining for spore forming bacteria, catalase reaction, and growth in anaerobic conditions, $\mathrm{KNO}_{3}$ reduction and indole production [17].

\section{Bacterial strains and culture conditions}

Except when cited, indigenous LAB were grown in LAPTg broth for $18 \mathrm{hr}$ at $37^{\circ} \mathrm{C}$, while Bacillus were grown under the same conditions in nutrient broth. Specific fish pathogens: Streptococcus agalactiae ATCC 27956, Streptococcus dysagalactiae subsp. dysagalactiae ATCC 27957, Lactococcus garvieae CRL 1828 (isolated from Lithobates catesbeianus) and L. garvieae (isolated from cows affected with mastitis) were grown in the conditions stated for LAB; other fish pathogens: Aeromonas salmonicida ATCC 33658, Yersinia ruckeri ATCC 29473, Klebsiella $s p$. (isolated from non-healthy fishes), Citrobacter freundii $\mathrm{CA}$ and $\mathrm{CB}$ (isolated from L. catesbeianus specimens) and meat spoilage bacteria: Listeria monocytogenes Scott A (isolated from meat), Pseudomonas aeruginosa 07 and 47 (isolated from L. catesbeianus specimens), Staphylococcus aureus (isolated from a clinical human sample), Escherichia coli M20DN3 and Salmonella enteritidis (isolated from meat) were grown in brain heart infusion (BHI) broth (Britannia) and/ or nutrient broth for $8 \mathrm{hr}$ at $37^{\circ} \mathrm{C}$.

\section{Screening of beneficial properties}

Hydrogen peroxide production: The hydrogen peroxide $\left(\mathrm{H}_{2} \mathrm{O}_{2}\right)$ production was qualitatively determined by the plate method, employing horseradish peroxidase incorporated in 3,3',5,5'-tetramethyl-benzidine (TMB) agar medium [18]. Isolates grown as cited before were centrifuged at $3,000 \times \mathrm{g}$ for $5 \mathrm{~min}$, cells were washed twice with sterile saline solution and streaked in MRS plates containing $1 \mathrm{mM} \mathrm{TMB}$ and $2 \mathrm{U} / \mathrm{mL}$ peroxidase. After incubation for $48 \mathrm{hr}$, the plates were exposed to air. According to the color intensity acquired by the colonies, the isolates were classified as strong (blue), medium (brown), scarcely (light brown) or negative (white colonies) producers.

Production of antagonistic substances: The production of antimicrobial metabolites of the isolates was tested using the agar-well diffusion assay. Selected isolates were grown for $18 \mathrm{hr}$ at $37^{\circ} \mathrm{C}$ in LAPTg broth and centrifuged at $3,000 \times \mathrm{g}$ for $10 \mathrm{~min}$ at $4^{\circ} \mathrm{C}$. Supernatants were fractioned in two aliquots, one remained untreated and the other was neutralized, both were stored at $-20^{\circ} \mathrm{C}$ until use. The indicator strains were grown in $\mathrm{BHI}$ or nutrient broth up to half of the exponential growth phase and inoculated at a concentration of $1 \times 10^{6}$ colony forming units $/ \mathrm{ml}(\mathrm{CFU} / \mathrm{ml})$ in $20 \mathrm{ml}$ of nutrient or BHI soft agar $(0.7 \% \mathrm{w} / \mathrm{v})$ at $45^{\circ} \mathrm{C}$ and poured into Petri dishes. After solidification, 10 $\mathrm{mm}$ diameter wells were made into the agar, filled with $100 \mu \mathrm{l}$ of pure (untreated) or neutralized (treated) supernatants, allowed to diffuse into the agar for $1 \mathrm{hr}$ at room temperature and incubated at $37^{\circ} \mathrm{C}$ for $24 \mathrm{hr}$. The presence of antagonistic metabolites in the supernatants was revealed as an inhibitory area around the well. The inhibition was expressed, in millimeters, as the diameter of the inhibition halo.

Biosurfactants production: The detection of surfactants was carried out by the oil spreading technique. Thus, a Petri dish was filled with a mix of distilled water and vegetable oil in a proportion 1:1 avoiding the mixture of both phases. Twenty milliliters of cell-free

\begin{tabular}{|c|c|c|c|c|}
\hline & \multirow[t]{3}{*}{ Larvae } & \multicolumn{3}{|c|}{ Juveniles } \\
\hline & & \multicolumn{2}{|c|}{30 days old } & \multirow[t]{2}{*}{14 months old } \\
\hline & & In fishbowls & In artificial ponds & \\
\hline Number of animals & 2 & 6 & 3 & 3 \\
\hline Mean weight (g) & 0.0145 & 0.670 & 5.0 & 921.67 \\
\hline Mean length (cm) & 1.1 & 3.7 & 8.6 & 38.8 \\
\hline Sampling & \multicolumn{2}{|c|}{ Whole animal homogenate } & \multicolumn{2}{|c|}{$\begin{array}{l}\text { Dorsal and ventral skin, gills, anus and mouth swabbed. Anterior } \\
\text { middle and posterior intestine homogenate }\end{array}$} \\
\hline
\end{tabular}

Table 1: Animals sampled in summer. 
Citation: Guidoli MG, Santinón JJ, Pasteris SE, Sánchez S, Nader-Macías MEF (2015) Isolation and Selection of Potentially Beneficial Autochthonous Bacteria for Piaractus mesopotamicus Aquaculture Activities. J Bioprocess Biotech 5: 254 doi:10.4172/2155-9821.1000254

Page 3 of 10

\begin{tabular}{|c|c|c|}
\hline & & \multicolumn{2}{|c|}{ Juveniles } \\
\cline { 2 - 3 } & $\mathbf{6}$ months old & Between 7 and 9 months old \\
\hline Number of animals & 7 & 3 \\
\hline Mean weight (g) & 55.0 & 196.43 \\
\hline Mean length (cm) & 18.6 & 30.7 \\
\hline Sampling & Dorsal and ventral skin, gills, anus and mouth swabbed. Anterior, middle and posterior intestine homogenates \\
\hline
\end{tabular}

Table 2: Animals sampled in winter.

supernatants of selected isolates were dropped into the liquid surface. The loss of the drop form and the mixture with the vegetal oil phase was considered as a positive result.

Degree of emulsification: Emulsifier activity was determined by adding $6 \mathrm{ml}$ kerosene or hexadecane to $4 \mathrm{ml}$ of cell free supernatant and vortexing at high speed for $2 \mathrm{~min}$. The emulsion index was considered as the height of the emulsion layer, divided by the total height of the liquid sample, multiplied by 100 . Quantifications were performed at 0 , $4,8,24,96$ and $360 \mathrm{hr}[19]$.

\section{Bacterial surface properties}

Hydrophobicity index: Hydrophobic characteristic of the bacterial surface was determined by the microbial adhesion to hydrocarbon method (MATH) [20] applying their capability of partition in water and a polar solvent (hexadecane). Bacterial cultures of $18 \mathrm{hr}$ at $37^{\circ} \mathrm{C}$ were centrifuged at 3,000 $\times \mathrm{g}$ for $5 \mathrm{~min}$, washed twice with sterile neutralized distilled water and resuspended to an optical density (O.D. ${ }_{600 \mathrm{~nm}}$ ) of 0.6 (initial O.D.). Aliquots of $1 \mathrm{ml}$ were added with $0.25 \mathrm{ml}$ of hexadecane, vortexed for $1 \mathrm{~min}$ and left to stand at room temperature for $15 \mathrm{~min}$ for separation of both phases. Finally, the O.D. ${ }_{600 \mathrm{~nm}}$ of the aqueous phase (final O.D.) was determined. The percentage of hydrophobicity was calculated using the following expression: Hydrophobicity\%=[(initial O.D.-final O.D.)/initial O.D] $\times 100$. The hydrophobicity score applied was: high (60-100\%), medium (30-59\%), low (0-29\%) [21].

Auto aggregation index: Aliquots of bacterial suspensions obtained as indicated previously were settled at room temperature for $4 \mathrm{hr}$, determining the O.D. ${ }_{600 \mathrm{~nm}}$ after 1 and $4 \mathrm{hr}$. The degree of auto aggregation was calculated according to the following equation: Auto aggregation index $=[($ initial O.D. - final O.D. $) /$ initial O.D $] \times 100$. The auto aggregation index score applied was: high (60-100\%), medium (30-59\%), low (0-29\%) [18].
Compatibility within selected isolates: The compatibility between selected isolates was performed by using the agar-well diffusion assay detailed above, using selected isolates as indicator and producer isolates strains. The appearance of inhibition halos indicated the incompatibility between the isolates.

Genotypic identification and BLAST comparison of selected strains: Microorganisms selected by their beneficial properties (Table 3) were submitted to genotypic identification. For this purpose the genomic DNA of each microorganism was extracted, purified and evaluated by PCR with specific primers in order to amplify de DNA region codifying for the region VI of the 16S RNA gene. The obtained fragment (of approximately $500 \mathrm{pb}$ ) was purified and sequenced. The results were analyzed online using the tools: http://rdp.cme.msu.edu/ html/analyses.html and http://www.ncbi.nlm.nih.gov/BLAST. All nucleotide sequences were submitted to the DDBJ / EMBL/GenBank databases. Fragments were also analyzed using the MEGABLAST software of the National Center for Biotechnology Information (NCBI) in order to search for the most similar sequences and thoroughly examine whether they were already used as probiotics in aquaculture or not.

\section{Results}

\section{Samples and isolation of cultivable microorganisms}

During the first isolation stage (autumn) 295 isolates were obtained, 41 of them were phenotypically identified as yeast, 64 as cocci and 190 as rods (Figure 1a). The second sampling (summer) resulted in 87 isolates, 47 of them were yeasts, while 34 and 6 were identified as cocci and rods, respectively (Figure $1 \mathrm{~b}$ ). In the third sampling (winter), 140 isolates were obtained, 3 of them were yeasts while 67 were cocci and 70 rods (Figure 1c). At the end of the isolation process, a total of 522 isolates were available (91 yeasts, 165 cocci and 266 rods) for further evaluation.

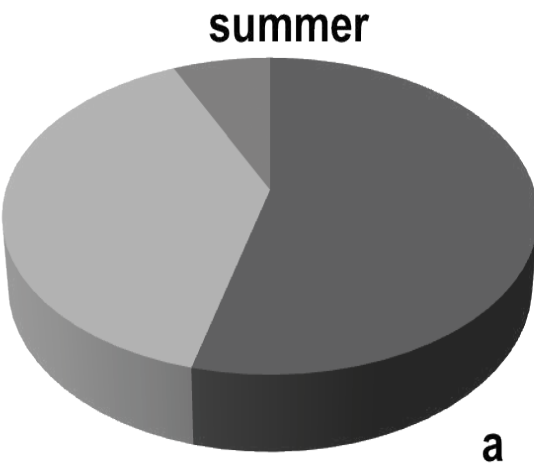

a

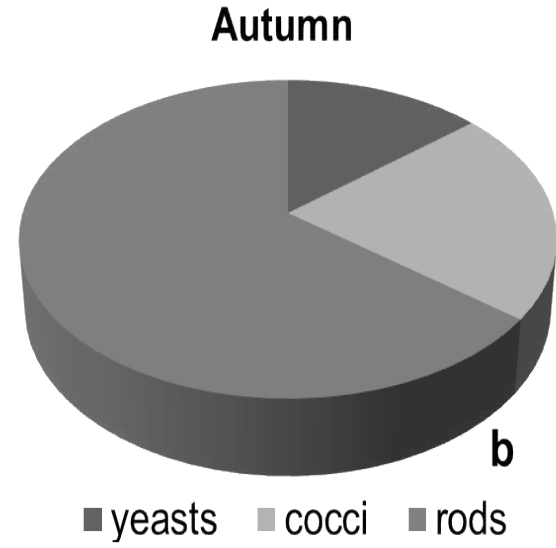

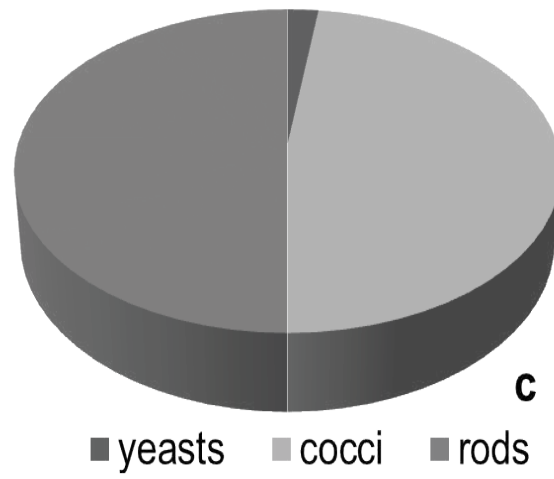

Figure 1: Relative proportion of the bacteria-yeast isolates from Piaractus mesopotamicus at different seasons. a: summer; b: autumn and c: winter. 
Citation: Guidoli MG, Santinón JJ, Pasteris SE, Sánchez S, Nader-Macías MEF (2015) Isolation and Selection of Potentially Beneficial Autochthonous Bacteria for Piaractus mesopotamicus Aquaculture Activities. J Bioprocess Biotech 5: 254 doi:10.4172/2155-9821.1000254

\section{Selection of beneficial microbial genera}

In this step, the 431 bacterial isolates were identified by phenotypic tests in order to preselect those of interest in this study. Out of the total, only 30 isolates were partially identified as LAB and 8 as Bacillus (Table $3)$. All of them were preselected to evaluate their beneficial properties.

\section{Screening of beneficial properties}

Thirty LAB and 8 Bacillus isolates were submitted to physiological studies to determine their beneficial characteristics by different assays related to surface properties and production of inhibitory metabolites.

\section{Hydrogen peroxide production}

The screening of $\mathrm{H}_{2} \mathrm{O}_{2}$ production on the $30 \mathrm{LAB}$ isolates showed that $15(50 \%)$ were not able to produce this antimicrobial metabolite, $8(26.67 \%)$ were scarcely producers (isolates $18,61 \mathrm{~B}, 70,71,72,73,74$ and 75 ), 6 (20\%) turned out to be medium producers (isolates 62, 63, 64, 65, 67 and 69) and only 1 (3.33\%) (isolate 66) was a strong producer microorganism. Bacillus isolates were unable to produce the oxidative metabolite (Figure 2).

\section{Production of antagonistic substances}

The evaluation of the antagonistic activity in the culture supernatant showed that 10 out of the $30 \mathrm{LAB}$ strains were unable to inhibit any of the food-borne bacteria and specific fish pathogens used in this study (Table 4). The other 20 isolates inhibited at least one of the indicator strains. Isolate 49 inhibited the growth of $P$. aeruginosa 47 , while isolate A74B inhibited S. aureus. LAB isolates 16, 18, 66, 69 and 75 inhibited $P$. aeruginosa strains, S. aureus and E. coli (indicators group 1). Isolate 65 inhibited the indicators group 1 (IG1) and the fish pathogen $Y$. ruckeri. Isolate 66 inhibited the growth of IG1 and Klebsiella sp. Isolate 62 inhibited the growth of IG1 and C. freundii CA, while isolates 63, 64, 71 and 73 were able to inhibit the IG1 and C. freundii CB. Isolate 70 inhibited the IG1 and two important fish pathogens; A. salmonicida and Klebsiella sp., while isolate 74 showed a similar pattern by inhibiting the growth of IG1, Klebsiella sp. and Y. ruckeri. Two of the $\mathrm{LAB}$ isolates with the broader inhibitory spectrum were $61 \mathrm{~B}$ and 72 inhibiting 9 and 7 of the indicator strains, respectively. The antagonistic activities described previously were due to the organic acids present in the culture supernatants. Isolate A34 inhibited the growth of $A$. salmonicida by organic acids and A. salmonicida and S. enteritidis by both, organic acids and non-acidic metabolites, observed in the inhibition caused by the neutralized supernatant. Isolate A35 showed a similar behavior, being able to inhibit the growth of $A$. salmonicida and $Y$. ruckeri only by organic acids and $S$. aureus by a combined effect of organic acids and non-acidic substances. On the other hand, only 3 of the Bacillus isolates were able to inhibit the growth of at least one of the indicator strains tested. Isolate A252 inhibits the growth ok Klebsiella sp. and $S$. enteritidis by a synergic effect of organic acids and nonacidic substances. Isolate A253 showed the same inhibitory spectrum as A252 inhibiting also the growth of $S$. aureus by organic acids only. Isolate A254 only inhibited the growth of $S$. aureus by a synergic effect of organic acids and non-acidic compounds (Table 4). It is important to point out that none of the isolates were able to inhibit the growth of $S$. agalactiae, $S$. dysagalactiae, $L$. monocytogenes or both strains of $L$. garvieae. Due to their inhibitory spectrum, the LAB isolates $61 \mathrm{~B}, 70,72$, 74, A34 and A35 as well as the Bacillus isolates A252, A253 and A254 were selected for further studies.

\section{Biosurfactants production}

All the LAB isolates were negative to the drop collapsing method.
However, only two Bacillus isolates (A254 and A256) were able to produce biosurfactants.

\section{Degree of emulsification}

Six Bacillus isolates (A252, A253, A254, A258, A259 and A260)

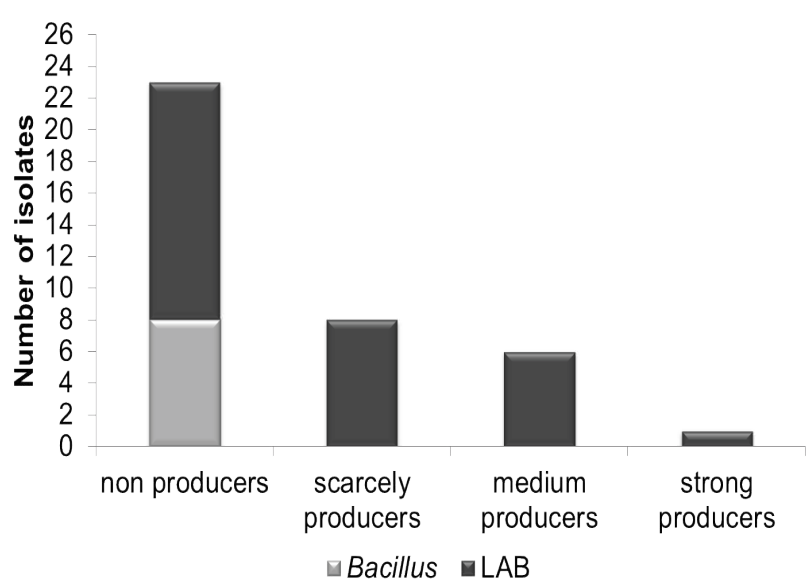

Figure 2: Qualitative detection of hydrogen peroxide production of isolated microorganisms.

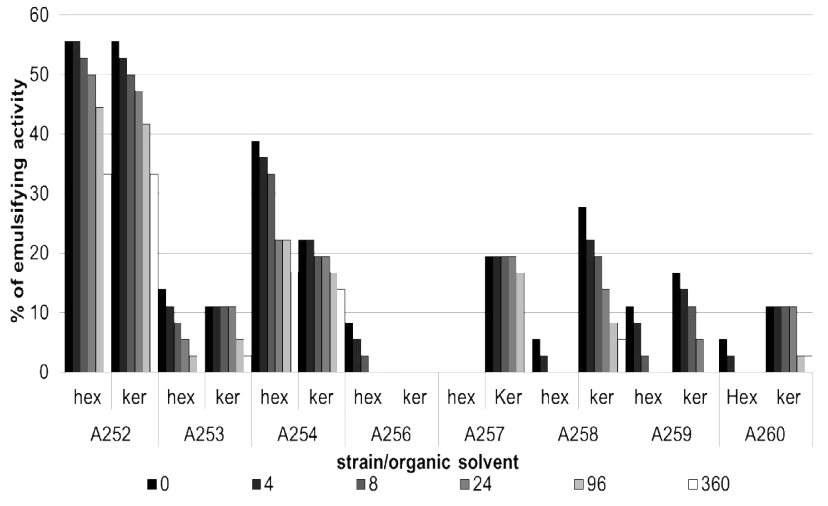

Figure 3: Emulsifying activity of Bacillus isolates on two different solvents. ker: kerosene and hex: hexadecane over the time.

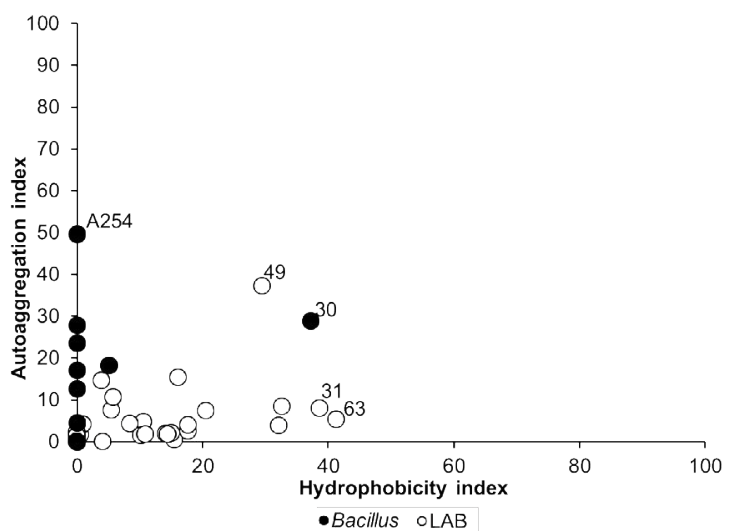

Figure 4: Cells surface properties of $L A B$ and Bacillus. Isolates showing the highest indexes were labeled with their respective names. 
were able to emulsify both organic solvents from time $0 \mathrm{~h}$, while only two Bacillus isolates (A252 and A254), maintained this ability up to the end of the experiment. Isolate A256 emulsified only hexadecane, while isolate A257 showed to emulsify kerosene (Figure 3). None of the LAB isolates demonstrated emulsification capacity.

\section{Cells surface's properties}

Hydrophobicity and auto aggregation: All the isolates showed hydrophobicity and auto aggregation values between 0 and $50 \%$ (Figure 4). However, LAB showed high hydrophobicity values and low auto aggregation percentages, while an opposite behavior were observed for Bacillus isolates. The results evidenced that $6(20 \%)$ LAB isolates (16, $30,31,49,63$ and 67) were moderately hydrophobic, while the surface of the other strains had a hydrophilic nature; all the Bacillus strains were hydrophilic. Only one LAB isolate (49) showed a medium auto aggregation percentage, while all the others presented low percentages. Only one Bacillus isolate (A254) has a medium auto aggregation percentage, while all the other strains showed low auto aggregation. Thus, auto aggregating LAB (30 and 49) and Bacillus (A252) and the hydrophobic $\operatorname{LAB}(30,31$ and 63$)$ were selected for further evaluations.

\section{Compatibility within selected isolates}

Compatibility tests were performed with all those isolates preselected after the screening of their surface and antagonistic characteristics and is summarized in Table 5.

The results indicate that two isolates (61B and 74 ) showed to inhibit the growth of other preselected microorganisms. On the other hand, LAB isolates $31,49,63$ and 72 growth scarcely in laboratory conditions; generating difficulties in the cells obtaining process for further assays. Then these six isolates were not included in the following studies.

On the basis of their beneficial properties, a group of 8 isolates were deposited into the culture collection of CERELA and considered for the design of a potentially probiotic veterinary product to be used in aquaculture of $P$. mesopotamicus. Selected microorganisms were: LAB isolate 30 (renamed as CRL 1940) for having medium of both, auto aggregation and hydrophobicity indexes; LAB isolate 66 (renamed as CRL 1939), for being the highest $\mathrm{H}_{2} \mathrm{O}_{2}$ producer; $\mathrm{LAB}$ isolate 70 (renamed as CRL 1941), for inhibiting two specific fish pathogens ( $A$. salmonicida and Klebsiela sp.) and LAB isolates A34 and A35 (renamed as CRL 1937 and CRL 1938, respectively), for inhibiting two specific fish pathogens (A. salmonicida and Y. ruckerii). The selected Bacillus isolates were A252, A253 and A254 for being able to inhibit at least one of the specific fish pathogens, for their emulsifying abilities and isolate A254 for having, also, the highest auto aggregation index and biosurfactants production. These isolates were later identified by genotypic methodology.

\section{Genotypic identification and BLAST comparison of selected isolates}

The genotypic identification and the beneficial properties of the selected strains, as well as the accession numbers of the nucleotide sequences (available at the DDBJ / EMBL / GenBank databases) are shown in Table 6.

Based on sequence alignments with these databases, out of the 100 results, a total of 93 and 5 sequences had an identity of $99 \%$ and $98 \%$, respectively, with the sequence obtained from isolates CRL 1940 and CRL 1941. Out of these 98 microorganisms only seven were isolated from water environments and none of them were assayed as probiotics in this particular area. A total of 99 sequences had an identity of
95\% with the sequence obtained from strain CRL 1939. Out of these microorganisms only three were isolated from water environments and none of them were assayed as probiotics. A total of 59 and 39 sequences had an identity of 100 and $99 \%$, respectively with the sequences obtained from isolates CRL 1937 and CRL1938. Out of these microorganisms 22 were isolated from water environments, being only 12 isolated from fishes. Out of this twelve, one was isolated from farmed Tilapia (Oreochromis niloticus) and only described and characterized by molecular biology, two of them were isolated from farmed seabass (Dicentrarchus labrax) and evaluated only by their ability to inhibit pathogens and foodborne pathogens in invitro assays, one was isolated from Grass carp (Ctenopharyngodon idellus) and evaluated in vitro only in its cellulolytic activity. Finally one was isolated from a freshwater fish and seven from Mullet (Mugil cephalus), all of them were annotated in GenBank as potentially probiotic bacteria, however these results are shown as unpublished and we have not found any related publications.

Results over the comparison of Bacillus strains showed that a total of 98 sequences had an identity of $99 \%$ with the sequence obtained from isolate A252. Out of these microorganisms 13 were isolated from water environments, being only 4 isolated from aquatic animals and only two evaluated in beneficial properties such as antitumoral in human gastric carcinoma cell lines (MC-4 and SGC-7901) and antimicrobial activity against plants pathogenic fungi. A total of 10 and 88 sequences had an identity of 100 and $99 \%$, respectively, with the sequences obtained from isolates A253 and A254. Out of these microorganisms one was isolated from sea sediments, two from algae and one from the digestive tract of a deep sea eel; none was tested as probiotic microorganisms in in vitro or in vivo assays.

\section{Discussion}

The introduction of $P$. mesopotamicus to the fish culture system in the northern region of Argentina led to an increase in the production of aquaculture facilities. This rise is explained by the intrinsic resistance of this autochthonous fish to the environmental conditions. On the other hand, the lack of knowledge on some critical factors like the biological cycle, food requirements and immune system together with the stressing conditions of intensive production systems and the increasing use of antibiotics induces a decrease in the number of animals. These factors led to the need of novel techniques to increase surviving and mean weight in order to obtain a higher number of animals in each stage of the biological cycle.

Probiotics emerge as a valid alternative to be widely and successfully applied all around the world in aquatic and terrestrial organisms. As demonstrated by Abraham et al. in ornamental fishes, the use of probiotic isolated from animals belonging to a different environment, makes uncertain the survival of probiotic microbes in the gastrointestinal tract of fishes [22]. These results support the need to isolate autochthonous microorganisms as putative probiotics to be tested in further "in vivo" assays.

The results obtained in the first stage of this study indicate that there is a relative decrease in the number of yeasts during the cold seasons when compared with the summer period. The relative proportions between cocci and rods showed no tendencies due to the high variability between the cultivable bacteria obtained. This variability was described previously as one of the most important features of the gastrointestinal microbiota in fish, by the different environmental conditions that are very susceptible to a long list of external and internal factors [23]. These results support the idea of a seasonal variation of the indigenous microbiome that could be related to the animal behavior and food 
Citation: Guidoli MG, Santinón JJ, Pasteris SE, Sánchez S, Nader-Macías MEF (2015) Isolation and Selection of Potentially Beneficial Autochthonous Bacteria for Piaractus mesopotamicus Aquaculture Activities. J Bioprocess Biotech 5: 254 doi:10.4172/2155-9821.1000254

Page 6 of 10

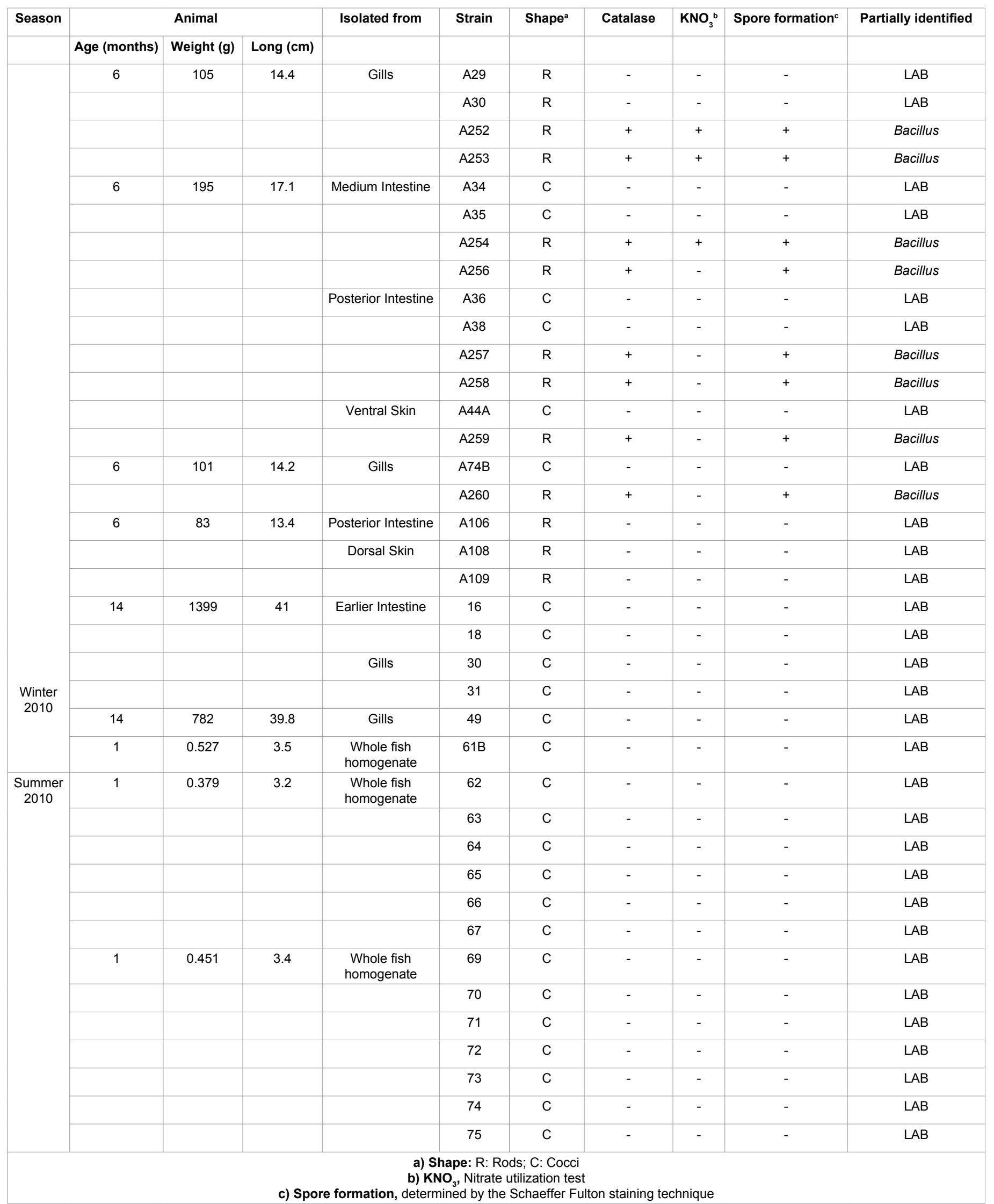

Table 3: Strains partially identified as Lactic Acid Bacteria (LAB) and belonging to the Bacillus genus by phenotypic tests. 
Citation: Guidoli MG, Santinón JJ, Pasteris SE, Sánchez S, Nader-Macías MEF (2015) Isolation and Selection of Potentially Beneficial Autochthonous Bacteria for Piaractus mesopotamicus Aquaculture Activities. J Bioprocess Biotech 5: 254 doi:10.4172/2155-9821.1000254

Page 7 of 10

\begin{tabular}{|c|c|c|c|c|c|c|c|c|c|c|c|c|c|c|c|c|c|c|c|c|}
\hline \multirow[t]{3}{*}{ Isolate } & \multicolumn{4}{|c|}{$\begin{array}{c}P . \\
\text { aeruginosa }\end{array}$} & \multirow{2}{*}{\multicolumn{2}{|c|}{ S. aureus }} & \multirow{2}{*}{\multicolumn{2}{|c|}{ E. coli }} & \multicolumn{2}{|c|}{$\begin{array}{c}A . \\
\text { Salmonicida }\end{array}$} & \multicolumn{2}{|c|}{$\begin{array}{c}\text { Y. } \\
\text { Ruckeri }\end{array}$} & \multicolumn{2}{|c|}{$\begin{array}{l}\text { Klebsiella } \\
\text { spp. }\end{array}$} & \multicolumn{2}{|c|}{$\begin{array}{c}P . \\
\text { vulgaris } C A\end{array}$} & \multicolumn{2}{|c|}{$\begin{array}{c}P . \\
\text { vulgaris } C B\end{array}$} & \multicolumn{2}{|c|}{ S. enteritidis } \\
\hline & \multicolumn{2}{|c|}{$\begin{array}{c}\text { Strain } \\
07\end{array}$} & \multicolumn{2}{|c|}{$\begin{array}{l}\text { Strain } \\
47\end{array}$} & & & & & & & & & & & & & & & & \\
\hline & SN & $\mathbf{N}$ & SN & $\mathbf{N}$ & SN & $\mathbf{N}$ & SN & $\mathbf{N}$ & SN & $\mathbf{N}$ & SN & $\mathbf{N}$ & SN & $\mathbf{N}$ & SN & $\mathbf{N}$ & SN & $\mathbf{N}$ & SN & $\mathbf{N}$ \\
\hline 16 & 2 & - & 4 & - & 1 & - & 4 & - & - & - & - & - & - & - & - & - & - & - & - & - \\
\hline 18 & 1.5 & - & 3 & - & 4.5 & - & 4.5 & - & - & - & - & - & - & - & - & - & - & - & - & - \\
\hline 30 & - & - & - & - & - & - & - & - & - & - & - & - & - & - & - & - & - & - & - & - \\
\hline 31 & - & - & - & - & - & - & - & - & - & - & - & - & - & - & - & - & - & - & - & - \\
\hline 49 & - & - & 1.5 & - & - & - & - & - & - & - & - & - & - & - & - & - & - & - & - & - \\
\hline 61B & 5 & - & 5 & - & 6 & - & 6.5 & - & 6 & - & 4 & - & 4 & - & 2 & - & 2 & - & - & - \\
\hline 62 & 4 & - & 5 & - & 6 & - & 5 & - & - & - & - & - & - & - & 2 & - & - & - & - & - \\
\hline 63 & 5 & - & 6 & - & 6 & - & 5.5 & - & - & - & - & - & - & - & - & - & 1 & - & - & - \\
\hline 64 & 5.5 & - & 6 & - & 5.5 & - & 6.5 & - & - & - & - & - & - & - & - & - & 2.5 & - & - & - \\
\hline 65 & 5 & - & 6.5 & - & 5 & - & 5 & - & - & - & 3.5 & - & - & - & - & - & - & - & - & - \\
\hline 66 & 3.5 & - & 6.5 & - & 6 & - & 6 & - & - & - & - & - & - & - & - & - & - & - & - & - \\
\hline 67 & 7 & - & 6 & - & 8 & - & 7 & - & - & - & - & - & 2 & - & - & - & - & - & - & - \\
\hline 69 & 5.5 & - & 6 & - & 6 & - & 7 & - & - & - & - & - & - & - & - & - & - & - & - & - \\
\hline 70 & 6.5 & - & 6 & - & 7 & - & 6.5 & - & 3 & - & - & - & 4 & - & - & - & - & - & - & - \\
\hline 71 & 6 & - & 6 & - & 5.5 & - & 6 & - & - & - & - & - & - & - & - & - & 3.5 & - & - & - \\
\hline 72 & 6.5 & - & 6.5 & - & 3.5 & - & 7 & - & - & - & - & - & 3.5 & - & 3 & - & 1 & - & - & - \\
\hline 73 & 5.5 & - & 6 & - & 3 & - & 7 & - & - & - & - & - & - & - & - & - & 2.5 & - & - & - \\
\hline 74 & 7 & - & 8 & - & 3.5 & - & 6 & - & - & - & 2 & - & 2 & - & - & - & - & - & - & - \\
\hline 75 & 7 & - & 6 & - & 3 & - & 6.5 & - & - & - & - & - & - & - & - & - & - & - & - & - \\
\hline A29 & - & - & - & - & - & - & - & - & - & - & - & - & - & - & - & - & - & - & - & - \\
\hline A30 & - & - & - & - & - & - & - & - & - & - & - & - & - & - & - & - & - & - & - & - \\
\hline A34 & - & - & - & - & - & - & - & - & 7 & - & 11 & 5 & - & - & - & - & - & - & 2 & 1 \\
\hline A35 & - & - & - & - & 7 & 3 & - & - & 7 & - & 7 & - & - & - & - & - & - & - & - & - \\
\hline A36 & - & - & - & - & - & - & - & - & - & - & - & - & - & - & - & - & - & - & - & - \\
\hline A38 & - & - & - & - & - & - & - & - & - & - & - & - & - & - & - & - & - & - & - & - \\
\hline A44A & - & - & - & - & - & - & - & - & - & - & - & - & - & - & - & - & - & - & - & - \\
\hline A74B & - & - & - & - & 7 & - & - & - & - & - & - & - & - & - & - & - & - & - & - & - \\
\hline A106 & - & - & - & - & - & - & - & - & - & - & - & - & - & - & - & - & - & - & - & - \\
\hline A108 & - & - & - & - & - & - & - & - & - & - & - & - & - & - & - & - & - & - & - & - \\
\hline A109 & - & - & - & - & - & - & - & - & - & - & - & - & - & - & - & - & - & - & - & - \\
\hline A252 & - & - & - & - & - & - & - & - & - & - & - & - & 11 & 11 & - & - & - & - & 9 & 7 \\
\hline A253 & - & - & - & - & 7 & - & - & - & - & - & - & - & 7 & 7 & - & - & - & - & 9 & 7 \\
\hline A254 & - & - & - & - & 10 & 10 & - & - & - & - & - & - & - & - & - & - & - & - & - & - \\
\hline A256 & - & - & - & - & - & - & - & - & - & - & - & - & - & - & - & - & - & - & - & - \\
\hline A257 & - & - & - & - & - & - & - & - & - & - & - & - & - & - & - & - & - & - & - & - \\
\hline A258 & - & - & - & - & - & - & - & - & - & - & - & - & - & - & - & - & - & - & - & - \\
\hline A259 & - & - & - & - & - & - & - & - & - & - & - & - & - & - & - & - & - & - & - & - \\
\hline A260 & - & - & - & - & - & - & - & - & - & - & - & - & - & - & - & - & - & - & - & - \\
\hline
\end{tabular}

Table 4: Inhibitory spectrum of the selected strains against food borne and specific fish pathogens as indicator strains. 
Citation: Guidoli MG, Santinón JJ, Pasteris SE, Sánchez S, Nader-Macías MEF (2015) Isolation and Selection of Potentially Beneficial Autochthonous Bacteria for Piaractus mesopotamicus Aquaculture Activities. J Bioprocess Biotech 5: 254 doi:10.4172/2155-9821.1000254

Page 8 of 10

\begin{tabular}{|c|c|c|c|c|c|c|c|}
\hline \multirow[t]{3}{*}{ Isolates } & \multicolumn{2}{|c|}{ Antagonistic substances } & \multicolumn{2}{|c|}{ Cell surface's properties } & \multicolumn{2}{|c|}{ Emulsifying activity (h) } & \multirow{3}{*}{$\begin{array}{l}\text { Biosurfactants } \\
\text { production }\end{array}$} \\
\hline & \multirow[t]{2}{*}{$\mathrm{H}_{2} \mathrm{O}_{2}$} & \multirow[t]{2}{*}{ Inhibition } & \multirow{2}{*}{$\begin{array}{l}\text { Auto aggregation } \\
\text { Index (\%) }\end{array}$} & \multirow[t]{2}{*}{$\begin{array}{l}\text { Hydrophobicity } \\
\text { index (\%) }\end{array}$} & & & \\
\hline & & & & & Hex & Ker & \\
\hline 18 & + & NO & 10.51 & 5.82 & - & - & - \\
\hline 62 & ++ & NO & 0.33 & 15.53 & - & - & - \\
\hline 64 & ++ & NO & 4.73 & 10.66 & - & - & - \\
\hline 66 & +++ & NO & 2.40 & 17.78 & - & - & - \\
\hline 69 & ++ & NO & 1.95 & 15.05 & - & - & - \\
\hline 71 & + & NO & 4.8 & 8.50 & - & - & - \\
\hline 73 & + & NO & 1.78 & 10.96 & - & - & - \\
\hline 75 & + & NO & 3.91 & 17.69 & - & - & - \\
\hline A34 & - & YES & 7.53 & 5.56 & - & - & - \\
\hline A35 & - & YES & 4.04 & 1.00 & - & - & - \\
\hline A256 & - & NO & 17.02 & 0.00 & 8 & - & + \\
\hline 49 & - & NO & 37.20 & 29.49 & - & - & - \\
\hline 31 & - & NO & 7.89 & 38.68 & - & - & - \\
\hline 61B & + & YES & 7.31 & 20.54 & - & - & - \\
\hline 65 & ++ & YES & 2.40 & 17.78 & - & - & - \\
\hline 67 & ++ & YES & 8.38 & 32.71 & - & - & - \\
\hline 70 & + & YES & 1.81 & 14.19 & - & - & - \\
\hline 72 & + & YES & 1.44 & 10.24 & - & - & - \\
\hline 74 & + & YES & 1.69 & 14.45 & - & - & - \\
\hline 63 & ++ & NO & 5.23 & 41.37 & - & - & - \\
\hline 30 & - & NO & 28.93 & 37.21 & - & - & - \\
\hline A252 & - & YES & 0.00 & 0.00 & 360 & 360 & - \\
\hline A253 & - & YES & 23.62 & 0.00 & 96 & 360 & - \\
\hline A254 & - & YES & 49.63 & 0.00 & 360 & 360 & + \\
\hline
\end{tabular}

Table 5: Beneficial properties of preselected isolates.

\begin{tabular}{|c|c|c|c|c|c|c|c|c|c|}
\hline Isolate & Strain & $\begin{array}{c}\text { Genotypic } \\
\text { identification }\end{array}$ & $\begin{array}{c}\text { GenBank } \\
\text { accession } \\
\text { numbers }\end{array}$ & $\begin{array}{c}\mathrm{H}_{2} \mathrm{O}_{2} \\
\text { Production }\end{array}$ & $\begin{array}{c}\text { Auto } \\
\text { aggregation } \\
\text { Index }(\%)\end{array}$ & $\begin{array}{l}\text { Hydrophobicity } \\
\text { Index (\%) }\end{array}$ & $\begin{array}{c}\text { Inhibition of } \\
\text { microorganisms }\end{array}$ & $\begin{array}{c}\text { Biosurfactants } \\
\text { Production }\end{array}$ & $\begin{array}{c}\text { Emulsifying } \\
\text { activity }\end{array}$ \\
\hline 30 & CRL1940 & $\begin{array}{l}\text { Enterococcus } \\
\text { faecium }\end{array}$ & KJ740155 & - & 28.93 & 37.21 & - & - & - \\
\hline 66 & CRL1939 & $\begin{array}{l}\text { Pediococcus } \\
\text { acidilactici }\end{array}$ & KJ740154 & +++ & 15.23 & 16.18 & $\begin{array}{l}P . \text { aeruginosa, } S \text {. } \\
\text { aureus, E. coli }\end{array}$ & - & - \\
\hline 70 & CRL1941 & $\begin{array}{l}\text { Enterococcus } \\
\text { faecium }\end{array}$ & KJ740156 & + & 1.81 & 14.19 & $\begin{array}{l}\text { P. aeruginosa, S. } \\
\text { aureus, E. coli, } \\
\text { A. salmonicida, } \\
\text { Klebsiella spp. }\end{array}$ & - & - \\
\hline A34 & CRL1937 & $\begin{array}{l}\text { Enterococcus } \\
\text { faecium }\end{array}$ & KJ740152 & - & 7.53 & 5.56 & $\begin{array}{l}\text { A. salmonicida, Y. } \\
\text { ruckerii, S. } \\
\text { enteritidis }\end{array}$ & - & - \\
\hline A35 & CRL1938 & $\begin{array}{l}\text { Enterococcus } \\
\text { faecium }\end{array}$ & KJ740153 & - & 4.04 & 1.00 & $\begin{array}{l}\text { S. aureus, } A . \\
\text { salmonicida, Y. } \\
\text { ruckerii }\end{array}$ & - & - \\
\hline A252 & A252 & Bacillus subtilis & KJ754388 & - & 0.00 & 0.00 & $\begin{array}{c}\text { S. enteritidis, Klebsiella } \\
\text { spp. }\end{array}$ & - & + \\
\hline A253 & A253 & Bacillus subtilis & KJ740157 & - & 23.62 & 0.00 & $\begin{array}{l}\text { S. aureus, S. enteritidis, } \\
\text { Klebsiella spp. }\end{array}$ & - & + \\
\hline A254 & A254 & Bacillus subtilis & KJ740158 & - & 49.63 & 0.00 & S. aureus & + & + \\
\hline
\end{tabular}

Table 6: Selected strains for in vivo assays.

intake during the cold seasons, period in which animals eat less and consequently show a slower growth than in wormer seasons.

The indigenous microbiome of the gastrointestinal tract of fishes consists in a huge variety of microorganisms in which only some species can be considered as beneficial. Then, it is necessary to determine which groups or genera can be considered as potentially beneficial organisms. In the last years, specific entities have published different categories of "secure" microorganisms such as the GRAS (Generally regarded as Safe), FGM (Food Grade Microorganisms) and QPS (Qualified Presumptive as Safe) qualifications. Some LAB, and Bacillus species are included into these classifications. Based on these observations, the following aim of this research was to partially identify those isolates belonging to both groups. Only $30 \mathrm{LAB}$ and 8 Bacillus isolates were obtained, representing only a $5.75 \%$ and a $1.53 \%$ of the total isolations, respectively. These results are in agreement with Sakata (1990), who establishes that Gram negative facultative anaerobes are the prevalent microorganisms in the digestive tract and symbiotic anaerobes could be 
dominant in the posterior intestine of some herbivorous tropical fish, while Aeromonas, Plesiomonas, and Enterobacteriaceae are dominant in freshwater fish [24]. The low incidence of LAB in P. mesopotamicus evidenced in this work, agrees with the fact that, although they are not dominant in the indigenous intestinal microbiota of freshwater fish, some of them can colonize the gut $[9,25]$. The next step of the work was the evaluation of the beneficial properties of the LAB and Bacillus isolates. The hydrogen peroxide production is a desirable characteristic in potentially probiotics for its synergic action together with organic acids against pathogens and due to the reduction of potentially opportunistic pathogens in aquatic environments $[6,26]$. The screening of the $\mathrm{H}_{2} \mathrm{O}_{2}$ production led to the preselection of $15 \mathrm{LAB}$ isolates $(50 \%$ of the total LAB) that produced the oxidative metabolite. Similar results were published by Pasteris et al. and Montel Mendoza et al. for different areas in raniculture facilities [17,27].

The production of antagonistic substances was also studied. Results indicate that 15 out of the 38 isolates were unable to inhibit the growth of assayed indicators. The preselection criterion for this stage was the ability to inhibit specific fish pathogens (A. salmonicida, Y. ruckeri or Klebsiella sp.). Thus, $12 \mathrm{LAB}$ and 3 Bacillus isolates were preselected.

The exogenous administration of surfactants or substances that promote its secretion is considered an adequate treatment for altered gastric mucosal barrier [28]. Besides, these substances are also promising compounds often showing antimicrobial and anti-adhesive properties, penetrating and removing mature biofilms from unanimated surfaces [29]. A wide range of microorganisms can produce these active compounds, mainly those belonging to the genus Bacillus. In this study the screening of biosurfactant-producing microorganisms was carried out using different methods. The production of biosurfactants and the capability of emulsify organic solvents was a selection criterion. 2 Bacillus isolates positive to the oil spreading technique, and 3 Bacillus isolates able to generate the most stable emulsions under the cited conditions were preselected.

The adherence to the intestinal mucus layer is another important selection criterion for beneficial microorganisms and considered the first and key step in host colonization [30]. However, the difficulties in studying the bacterial adhesion through in vivo led to the use of in vitro models for the preliminary screening of potentially adherent isolates [31]. As a general rule, isolates adhering well to hydrocarbons are considered to be hydrophobic and those adhering poorly are considered hydrophilic. Then, hydrophobicity could indicate an advantage and important feature for bacterial maintenance in the gastrointestinal tract [32], being reported to be a qualitatively valid method to estimate the ability of an isolate to adhere to epithelial cells based on its hydrophobicity [33]. Based on the results obtained in this work, $4 \mathrm{LAB}$ and one Bacillus isolates were preselected based on their highest hydrophobicity and auto aggregation indexes.

The inclusion of more than one strain in a probiotic formula, demands to perform compatibility assays. From the 24 preselected isolates only $\mathrm{LAB}$ isolates $61 \mathrm{~B}$ and 74 were incompatible and therefore they cannot be included in a mixed probiotic product.

From the 38 isolates obtained in the first stage of the study, 8 were selected as potentially probiotic candidates for aquaculture of $P$. mesopotamicus taking into account general guidelines [34]. Selected microorganisms were: Pediococcus acidilactici CRL 1939 (isolate 66) for its high hydrogen peroxide production, Enterococcus faecium CRL 1941 (isolate 70) for its $\mathrm{H}_{2} \mathrm{O}_{2}$ production and ability to inhibit two fish specific pathogens, E. faecium CRL 1940 (isolate 30) for its high hydrophobicity and auto aggregation indexes, E. faecium CRL 1937 (isolate A34) and CRL 1938 (A35) for their ability to inhibit two fish specific pathogens, Bacillus subtilis A252, A253 and A254 for being the only Bacillus isolates with inhibitory spectrum and emulsifying activity, A254 also showed a medium auto aggregation index and the production of biosurfactantes. The MEGABLAST comparison using de NCBI data base showed that there are no registrations of genetically similar microorganisms used as probiotics in aquaculture. Thus, selected microorganisms were included in the strain collection of the Laboratorio de Sanidad Animal of the Estación Experimental Agropecuaria Rafaela belonging to the Instituto Nacional de Tcnología Agropecuaria (INTA) under Budapest treaty [35].

The results obtained in this work represent the basis of the "in vivo" experiments planned to be performed in the next stage, as a way to determine the most suitable group of microorganisms, dose and biological cycle stage of the animals to be administered to fishes.

\section{Acknowledgements}

The Argentinian National Council of Scientific and Technical Researches (Consejo Nacional de Investigaciones Científicas y Técnicas - CONICET), projects numbers PIP 632 and PIP 744, together with the National Agency for Scientific and Technological Promotion (Agencia Nacional de Promoción Científica y Tecnológica - ANPCyT) through the Fund for Scientific and Technological Research (Fondo para la Investigación Científica y Tecnológica - FONCyT); projects numbers PICTO-UNNE-2007-161, PICTO-UNNE-2011-198, PICT-543 and PICT-1087; financed this study. Some of the results of this paper were included in a patent presentation in Argentina (INPI Exp 20130103820).

\section{References}

1. Aquaculture Directorate (2013) Aquaculture Bulletin. National Fishery Planning Under secretary of Fisheries and Aquaculture of the Nation.

2. Hernández Serrano $P$ (2005) Responsible use of antibiotics in aquaculture FAO Fisheries Technical Paper 469

3. WHO (1999) Food safety issues associated with products from aquaculture Report of a Joint FAO/NACA/WHO Study Group. World Health Organ Tech Rep Ser 883: 1-55.

4. Statens Offentliga Utrednigar-National Public Investigations from Sweden (SOU) (1997) Toxicological and related effects of antibacterial feed aditivies. Document No. 132

5. Reig M, Toldrá $F(2008)$ Veterinary drug residues in meat: Concerns and rapid methods for detection. Meat Sci 78: 60-67.

6. Verschuere L, Rombaut G, Sorgeloos P, Verstraete W (2000) Probiotic bacteria as biological control agents in aquaculture. Microbiol Mol Biol Rev 64: 655-671.

7. Nayak SK, Mukherjee SC (2011) Screening of gastrointestinal bacteria of Indian major carps for a candidate probiotic species for aquaculture practices Aquacult Res 42: 1034-1041.

8. Lakshmi B, Viswanath B, Sai Gopal DV (2013) Probiotics as antiviral agents in shrimp aquaculture. J Pathog 2013: 424123

9. Ringø E, Vadstein O (1998) Colonization of Vibrio pelagius and Aeromonas caviae in early developing turbot (Scophthalmus maximus L.) larvae. J Appl Microbiol 84: 227-233.

10. Gildberg A, Mikkelsen H (1998) Effects of supplementing the feed of Atlantic cod (Gadus morhua) fry with lactic acid bacteria and immunostimulating peptides during a challenge trial with Vibrio anguillarum. Aquacult 167: 103-113.

11. Gram L, Melchiorsen J, Spanggaard B, Huber I, Nielsen TF (1999) Inhibition of Vibrio anguillarum by Pseudomonas fluorescens $\mathrm{AH} 2$, a possible probiotic treatment of fish. Appl Environ Microbiol 65: 969-973.

12. Gibson L, Woodworth J, George A (1998) Probiotic activity of Aeromonas media on the Pacific oyster, Crassostrea gigas, when challenged with Vibrio tubiashii. Aquacult 169: 111-120.

13. Queiroz J, Boyd C (1998) Effects of a bacterial inoculum in channel catfish ponds. J World Aquacult Soc 29: 67-73. 
Citation: Guidoli MG, Santinón JJ, Pasteris SE, Sánchez S, Nader-Macías MEF (2015) Isolation and Selection of Potentially Beneficial Autochthonous Bacteria for Piaractus mesopotamicus Aquaculture Activities. J Bioprocess Biotech 5: 254 doi:10.4172/2155-9821.1000254

14. Sun YZ, Yang HL, Ma RL, Lin WY (2010) Probiotic applications of two dominant gut Bacillus strains with antagonistic activity improved the growth performance and immune responses of grouper Epinephelus coioides. Fish Shellfish Immunol 29: 803-809.

15. Ringø E, Gatesoupe FJ (1998) Lactic acid bacteria in fish: a review. Aquacult 160: 177-203.

16. Iqbal MZ, Qadir MI, Hussain T, Janbaz KH, Khan YH, et al. (2014) Review: probiotics and their beneficial effects against various diseases. Pak J Pharm Sci 27: 405-415

17. Mendoza GM, Pasteris SE, Ale CE, Otero MC, Bühler MI, et al. (2012) Cultivable microbiota of Lithobates catesbeianus and advances in the selection of lactic acid bacteria as biological control agents in raniculture. Res Vet Sci 93: 1160-1167.

18. Tomás MS, Claudia Otero M, Ocaña V, Elena Nader-Macías M (2004) Production of antimicrobial substances by lactic acid bacteria I: determination of hydrogen peroxide. Methods Mol Biol 268: 337-346.

19. Cooper DG, Goldenberg BG (1987) Surface-active agents from two bacillus species. Appl Environ Microbiol 53: 224-229.

20. Rosenberg M, Doyle RJ (1990) Microbial cell surface hydrophobicity: History, measurement, and significance. In: Doyle RJ, Rosenberg M (Eds.) Microbial cell surface hydrophobicity. ASM Inc., Washington, USA, pp. 1-38.

21. Ocana VS, Bru E, De Ruiz Holgado AA, Nader-Macias ME (1999) Surface characteristics of lactobacilli isolated from human vagina. J Gen Appl Microbiol 45: 203-212.

22. Abraham J, Mondal S, Babu S (2008) Effect of commercial aquaculture probiotic and fish gut antagonistic bacterial flora on the growth and disease resistance of ornamental fishes Carassius auratus and Xiphophorus helleri. J Fish Aquat Sci 25: 27-30.

23. Gatesoupe FJ (2008) Updating the importance of lactic acid bacteria in fish farming: natural occurrence and probiotic treatments. J Mol Microbiol Biotechnol 14: 107-114

24. Sakata T (1990) Microflora in the digestive tract of fish and shellfish. In: Lesel $R$ (Ed.) Microbiology in poecilotherms. Elsevier, Amsterdam.
25. Denev S, Staykov Y, Moutafchieva R, Beev G (2009) Microbial ecology of the gastrointestinal tract of fish and the potential application of probiotics and prebiotics in finfish aquaculture. Int Aquat Res 1: 1-29.

26. Farzanfar $A$ (2006) The use of probiotics in shrimp aquaculture. FEMS Immuno Med Microbiol 48: 149-158.

27. Pasteris SE, Babot GR, Otero MC, Bühler MI, Nader-Macías ME (2009) Beneficial properties of lactic acid bacteria isolated from a Rana catesbeiana hatchery. Aquacult Res 40: 1605-1615.

28. Hills BA (1996) Gastric surfactant and the hydrophobic mucosal barrier. Gut 39: 621-624.

29. Rodrigues $L$, van der Mei $H$, Teixeira JA, Oliveira R (2004) Biosurfactant from Lactococcus lactis 53 inhibits microbial adhesion on silicone rubber. Appl Microbiol Biotechnol 66: 306-311.

30. Rinkinen M, Westermarck E, Salminen S, Ouwehand AC (2003) Absence of host specificity for in vitro adhesion of probiotic lactic acid bacteria to intestinal mucus. Vet Microbiol 97: 55-61.

31. Duary RK, Rajput YS, Batish VK, Grover S (2011) Assessing the adhesion of putative indigenous probiotic lactobacilli to human colonic epithelial cells. Indian J Med Res 134: 664-671.

32. Naidu AS, Bidlack WR, Clemens RA (1999) Probiotic spectra of lactic acid bacteria (LAB). Crit Rev Food Sci Nutr 39: 13-126.

33. Klayraung S, Viernstein H, Sirithunyalug J, Okonogi S (2008) Probiotic Properties of Lactobacilli Isolated from Thai Traditional Food. Sci Pharm 76: 485-503.

34. Reid G, Sanders ME, Gaskins HR, Gibson GR, Mercenier A, et al. (2003) New scientific paradigms for probiotics and prebiotics. J Clin Gastroenterol 37: 105118.

35. CONICET (Consejo Nacional de Investigaciones Científicas y Técnicas) (2013) Composición para mejorar la cría de peces de agua dulce y método de mejoramiento de la cría. Country granting the patent: Argentina. Patent number: 20130103820 